\title{
Experience in treatment of patients with severe influenza with viral pneumonia in ICU
}

\begin{abstract}
Objective: To explore the experience of severe influenza A viral pneumonia treatment.

Methods: The clinical data and treatment of 6 cases of severe influenza with virus RNApositive pneumonia were analyzed.

Results: 3 cases of new H1N1 influenza, 3 cases did not do further nucleic acid subtype identification, patients were treated with oseltamivir. 3 patients with invasive pulmonary aspergillosis, 4 patients received invasive mechanical ventilation, 2 cases of pneumothorax. 3 patients received continuous hemofiltration for acute renal injury, 4 with ventilatorassociated pneumonia in 5 patients with mechanical ventilation, and 5 patients died.
\end{abstract}

Conclusion: Suffering from severe underlying disease, the use of glucocorticoids, deep sedation, secondary pulmonary infection of influenza A virus causes severe pneumonia and high mortality.

Keywords: influenza a virus, pneumonia, acute respiratory distress syndrome, mechanical ventilation
Volume 7 Issue 6 - 2017

\author{
Noor Mohammad,' Huang Xiao-Fang,' Shan \\ Ti-Yao, ${ }^{2}$ Zhang Fan, ${ }^{2}$ MA Yang,, Guo Hai- \\ Peng, ${ }^{2}$ Zhai Qian, ${ }^{2}$ Ding Shi-Fang ${ }^{2}$ \\ 'Department of Critical Care Medicine, Qilu hospital of \\ Shandong University, China \\ ${ }^{2}$ Second Ward Qilu Hospital of Shandong University, Intensive \\ Care Medicine, China
}

Correspondence: Ding Shifang, Second Ward Qilu Hospital of Shandong University, Intensive Care Medicine, CN, XI road, Lixia District, Jinan City, Shandong province, China, Tel 1856008 I003, Email|8560081003@|63.com

Received: May 08, 2017 | Published: May II, 2017

\section{Introduction}

China has been infected with highly pathogenic avian influenza, H7N9 avian influenza and influenza A H1N1 influenza as a class $\mathrm{B}$ infectious diseases, group management, ${ }^{1-3}$ to control disease outbreaks, reduce mortality, play an important role. Along with the dangers of influenza virus to reduce, on November 4, 2013 national influenza a viruses according to the seasonal flu management, ${ }^{4}$ and release of human infection with highly pathogenic avian influenza and H7N9 category management. and the lifting of human infection with highly pathogenic avian influenza and H7N9 class A management. Lack of scientific understanding of influenza a viruses, fears of its harmful effects, affect the success rate of treatment of such diseases.

From February 25 to May 25, 2016, Qilu Hospital Molecular Biology Laboratory tested influenza virus nucleic acid for 73 respiratory specimens and another 3 specimen of broncho-alveolar lavage fluid (BALF) to Beijing Chaoyang Hospital to detect influenza $A$ virus. The 14 people were diagnosed with influenza A, of which 6 patients were treated in the second ward of the Department of Critical Care Medicine. The 6 patients received a large room without isolation facilities, ${ }^{5}$ according to standard preventive measures to treat patients, no more hospital patients and health care workers were infected. Analysis of 6 cases of patients with severe influenza treatment lessons, will provide valuable experience to improve treatment success rates in the future.

\section{Clinical information}

In case 1: A 54years old woman was well before. Gastrointestinal endoscopy was done on $28^{\text {th }}$ December 2015 due to abdominal pain. On $6^{\text {th }}$ January 2016 patient developed dyspnea and intermittent fever. On $8^{\text {th }}$ January aggravated shortness of breath, which aggravated by movement and patient admitted in a local hospital for treatment.

The white blood cells were $3.95 \times 109 / \mathrm{L}$, the proportion of neutrophils was $87.6 \%$, the calcitonin (PCT) was $0.088 \mathrm{ng} / \mathrm{mL}$, the C-reactive protein (CRP) was $27.4 \mathrm{mg} / \mathrm{L}$ and the ESR was $52 \mathrm{~mm} / \mathrm{h}$. CT showed diffuse exudation of the lungs. Arterial blood gas: PH7.49,
$\mathrm{PaCO} 236 \mathrm{mmHg}, \mathrm{PaO}, 60 \mathrm{mmHg}$. Suspected influenza A, given oseltamivir capsules $150 \mathrm{mg}$, twice a day. Respiratory distress was not relief, at 12:00 on 12 ${ }^{\text {th }}$ January with "severe pneumonia and lungderived ARDS (severe)" admitted to Qilu hospital. During admission patient was severely ill, APACHE II 11, SOFA 5.on Noninvasive mechanical ventilation (NPPV) for 2 hours, with $15 \mathrm{~L} / \mathrm{min}$ oxygen support, oxygen saturation was maintaining $60 \%-70 \%$, tachycardia and respiratory distress were continuing, at 19: 03 oral tracheal intubation was done, invasive mechanical ventilation was started. $13^{\text {th }}$ January in the bleeding point. January $13^{\text {th }} 17: 00$ Continuous pulse contour cardiac output monitoring (PiCCO) shows 2016 8:00 neck subcutaneous emphysema was found, CT showed doublelung grindstone-like exudation, mediastinal emphysema. From January 12 to January 16, intravenous methylprednisolone 80mg, q $12 \mathrm{~h} ; 11^{\text {th }}$ January 19 intravenous methylprednisolone $120 \mathrm{mg}$, q12h; $120^{\text {th }}$ January 23 intravenous methylprednisolone 40mg, QD. $13^{\text {th }}$ January 2016 at 12:30 tracheotomy was done, trachea showed airway mucosal congestion, scattered, extravascular lung water $10.0 \mathrm{~mL} / \mathrm{kg}$, permeability index 1.9 .9 January 13 Lower respiratory tract attractant (TBA) Influenza A virus antigen negative (Colloidal gold method), January 18 alveolar lavage fluid (BALF) sent to Beijing Chaoyang Hospital show influenza virus nucleic acid positive, new H1N1 influenza virus nucleic acid negative. February 1 BALF specimens showed influenza A virus negative. January $12^{\text {th }}$ Day to January 18 intravenous infusion of immunoglobulin $20 \mathrm{~g}$ qd. On January 24 and January 29, the serum galactomannan index (GM) was 5.0 and 1.30 , and the serum and 3 BALF GM were $<0.5$ from January 13 to March 1, respectively. Intractable cough and man-machine confrontation, analgesic sedative muscle relaxation effect is poor. February 6 left pneumothorax, thoracic closed drainage. February 14 creatinine $287 \mu \mathrm{mol} / \mathrm{L}$, start bedside hemofiltration (CRRT). During the hospitalization, the occurrence of hydrocarbonase-resistant Acinetobacter baumannii (CR-AB)-induced pulmonary infection and left empyema, as well as hydrocarbon-resistant pneumonia Klebsiella sepsis. Oxygen and progressive deterioration, septic shock, multiple organ failure, Patient was died on $1^{\text {st }}$ March at 20:42. 
Case 2: A 77 years old male, With the history of 20years of hypertension, 4years of diabetes. On January $26^{\text {th }}, 2016$ body temperature was 39.2 ${ }^{\circ} \mathrm{C}$. On January $31^{\text {st }}$ body temperature was $40{ }^{\circ} \mathrm{C}$, with chest tightness, wheezing. Admitted to the Qilu hospital infection department, given cefoperazone/sulbactam, moxifloxacin, oseltamivir (75mg twice daily). February $1^{\text {st }}$ mask oxygen $10 \mathrm{~L} / \mathrm{min}$, oxygen saturation of about $75 \%, \mathrm{PaO}_{2} 45 \mathrm{mmHg}$, lactic acid $4.3 \mathrm{mmol} / \mathrm{L}$. White blood cells $6.88 \times 109 / \mathrm{L}$, the proportion of neutrophils $93.7 \%$, creatinine $365 \mu \mathrm{mol} / \mathrm{L}$. Given oral endotracheal intubation, invasive mechanical ventilation. The disease continued to deteriorate, February $2^{\text {nd }}$ at 16:58 with "severe pneumonia, septic shock, lung-derived ARDS (severe), acute kidney injury" admitted to the second ward of intensive care medicine and received CRRT t, APACHE II score of 20 points, SOFA score 8 points. On February $4^{\text {th }}$, PiCCO showed extravascular changes in pulmonary water in accordance with severe changes in lung-induced ARDS. February $4^{\text {th }}$ TBA Influenza A virus antigen test negative (colloidal gold method). February $5^{\text {th }}$ trachea showed BALF meat for the meat, the sample sent to Beijing Chaoyang Hospital confirmed influenza A virus positive nucleic acid, the new H1N1 influenza virus nucleic acid negative. During the treatment, ETA was cultured as $\mathrm{CR}-\mathrm{AB}$ and combined with the ring with tigecycline therapy. Chest radiograph showed large lungs seepage real shadow, to take a negative liquid balance and protective mechanical ventilation strategy, refractory hypoxemia does not relieve, and the emergence of refractory hypercapnia, septic shock, On February $13^{\text {th }}$ at 19: 03 patient was died.

Case 3: A 63years old women, with $\mathrm{H} / \mathrm{O}$ chronic obstructive pulmonary disease (COPD), repeated wheezing, cough, sputum for more than 20years which increased with fever for 10days, highest temperature of $39.5^{\circ} \mathrm{C}$. White blood cells $9.07 \times 109 / \mathrm{L}$, the proportion of neutrophils $75.6 \%$, CRP $88.9 \mathrm{mg} / \mathrm{L}$. CT showed chronic bronchitis, interstitial pneumonia, arterial blood gas $\mathrm{PH} 7.49, \mathrm{PaCO} 231 \mathrm{mmHg}$, $\mathrm{PaO}_{2} 54 \mathrm{mmHg}$. Outside the hospital to give piperacillin/tazobactam treatment for 9days, On March 16 $6^{\text {th }}, 2016$ 16:56 with "acute decompensated respiratory acidosis and hypoxemia" admitted to the second ward of intensive care medicine department, oral tracheal Intubation was done for mechanical ventilation. On March $9^{\text {th }}$ and March $14^{\text {th }}$, BALF specimens confirmed that influenza A (universal) influenza virus and influenza A (H1N1) were positive for influenza virus, nasal administration of oseltamivir $150 \mathrm{mg}$ twice daily. March 10 subcutaneous emphysema, chest radiograph showed mediastinal emphysema and pneumothorax, emergency thoracic closed drainage and tracheotomy were done. March $7^{\text {th }}$ serum, March $8^{\text {th }}$ and March $14^{\text {th }}$ BALF specimens GM were $0.03,0.22$ and 4.82 (reference value $<0.5$ ). Disease was worsens, On March $14^{\text {th }}$ at 16:00 patient was declared clinically death.

Case 4: A 46 years old male, was well enough, he was engaged for a long time in interior decoration and housing demolition. On March 1 $1^{\text {st }}, 2016$ due to "fever and cough for 5 days" stayed in a local hospital, his white blood cells were $4.8 \times 109 / \mathrm{L}, 72.1 \%$ neutrophils, chest radiograph shows bronchitis. Given roxithromycin as treatment, wheezing, shortness of breath increased, with lips cyanosis. On March $3^{\text {rd }}$, CT showed double-lung diffuse grinding glass changes, suggesting that infectious lesions. On March $4^{\text {th }}$ arterial blood gas shows $\mathrm{PaO}_{2} 24 \mathrm{mmHg}$, lactic acid $3.7 \mathrm{mmol} / \mathrm{L}$, Tracheal intubation was done for invasive mechanical ventilation, methylprednisolone, imipenem, oseltamivir and other treatment were given. On March $6^{\text {th }}$ at 9:09 admitted to the second ward of intensive care medicine department, APACHE II 29 points, SOFA 11 points. PiCCO showed extravascular lung water $21 \mathrm{~mL} / \mathrm{kg}$, permeability index 4.0. On March $8^{\text {th }}$ at 10:00 tracheotomy was done, analgesic and sedative and muscle relaxation strategies to maintain RASS- 2 points to +1 points. Tracheal microscope lumen a lot of watery mucus congestion and erosion, bleeding of mucous membrane of airway, ETA specimen shown in negative influenza a viral antigen detection (colloidal gold), viral (common) flu virus and influenza a (H1N1) influenza virus RNA positive. Feeding oseltamivir $150 \mathrm{mg}$, twice a day. On March $14^{\text {th }}$ and March $21^{\text {st }}$, On March $25^{\text {th }}$ influenza A (H1N1) influenza virus nucleic acid is still positive. Serum GM 0.21 and 0.20, respectively on March $6^{\text {th }}$ and March $15^{\text {th }}$, On March $6^{\text {th }}$, March $8^{\text {th }}$, and March $14^{\text {th }}$, and March $25^{\text {th }}$ GM BALF samples were 4.0, 3.0, 3.99, 3.25, combined with voriconazole and caspofungin in IPA. Disease progression, patients with acute kidney injury, between March $14^{\text {th }}$ and March $9^{\text {th }}$ at 22:00 CRRT intervention but hypoxaemia is improving steadily. On March $17^{\text {th }}$ methylprednisolone intravenous infusion 40mg QD, On March $23^{\text {rd }}$ tracheoscopy tracheal mucous membrane as shown in a large number of white pseudo-membranous attachment, mucosal erosion bleeding, tracheal mucosal examination of Aspergillus fumigates hyphae. In patients with refractory cough, man vs computer obviously, combined with dextromethorphan, Atracurium and other sedative and muscle relaxant. Oxygen demand enhanced and worsen, septic shock, on March 27 th at 7:41 patient was death.

Case 5: A 54years old women, farmer, history of hypertension and bronchiectasis for 20years, with the history of nephrotic syndrome and chronic renal insufficiency for 1.5 years. Edema occurs after February $19^{\text {th }}, 2016$ colds and wheezes increased $550 \mu \mathrm{mol} / 1$ creatinine. Received Continuous dialysis in 5times, from February $28^{\text {th }}$ to March $1^{\text {st }}$, methylprednisolone impact 3days, sequential highdose chemotherapy. March 3 cough up blood, approximately $150 \mathrm{~mL}$, with yellow-purulent sputum, a temperature of 38.5 degrees Celsius, on March $5^{\text {th }}$ at 8:07 stay in Nephrology, 12.9x109/L white blood cells, neutrophil percentage $89.3 \%$, haemoglobin $63.2 \mathrm{~g} / \mathrm{L}$, TC $6.3 \mathrm{mmol} / \mathrm{L}$, $6.89 \mathrm{mmol} / \mathrm{L}$ triglycerides, creatinine $606 \mu \mathrm{mol} / \mathrm{L}, 24 \mathrm{~h}$ urine protein 3.9G. Acute hemodialysis 1 , asthmatic deterioration associated with hypoxemia. March $9^{\text {th }}$ at 10:59 transfer to Intensive Care Medicine, cumulative prednisone dose $4315 \mathrm{mg}$, continuous NPPV treatment, lose red blood cells, the CRRT therapy. On March $10^{\text {th }}$ sputum specimen shows a (Universal) positive influenza virus nucleic acid, influenza a (H1N1) influenza virus nucleic acid negative, and given oseltamivir $150 \mathrm{mg}$, twice a day. On March $5^{\text {th }}$ and March $9^{\text {th }}$, sputum culture for Aspergillus fumigatus, serum GM 6.0 and 1.1 respectively on March $10^{\text {th }}$ and March $23^{\text {th }}$, caspofungin injection and voriconazole tablets in the treatment of invasive pulmonary aspergillosis. On March 12 $2^{\text {th }}$ at 8:05 transferred to the urology department, Dyspnea and hypoxemia deteriorate, $\mathrm{CT}$ double lung inflammation, bronchiectasis and multiple infections, some of the Mucus plug. On April $3^{\text {th }}$, patient was discharged. 5days after discharge from hospital, patient was died.

Case 6: A 28years old male, was well enough then he developed "cough, and sputum for 20 days, fever for 8 days, wheezing for 3 days" takes treatment outside the hospital but did not cured, On March $2^{\text {nd }}$, 2016 at 22:05 emergency admission to the second ward of ICU d. On February $28^{\text {th }}$ chest CT showed multiple pulmonary nodules, patchy high-density shadow, part of the ground-glass-like changes. The white blood cells were $5.42 \times 109 / \mathrm{L}$, the proportion of neutrophils was $87.6 \%$, PCT was $0.195 \mathrm{ng} / \mathrm{mL}$ and CRP was $21.1 \mathrm{mg} / \mathrm{L}$. Suspected viral pneumonia, given oseltamivir 150mg twice a day. Nasal oxygen, no breathing distress. On March 3 sputum specimens showed influenza A virus negative antigen test (colloidal gold method), influenza A (generic) influenza virus nucleic acid and influenza A (H1N1) virus nucleic acid negative. On March $4^{\text {th }}$, once again sent to the sputum specimens show type (general) influenza virus nucleic acid and influenza A(H1N1) virus nucleic acid positive. March 8 13:20 transfer isolation treatment, was discharged from hospital. 


\section{Discussion}

At present, Centers for disease control and prevention (CDC) is responsible for the influenza virus Antigen screening, influenza virus typing and confirmation work. ${ }^{6}$ Swine flu virus causes severe viral pneumonia, lower respiratory tract virus load than the upper respiratory tract and clear the slow, lower respiratory tract specimens should be at this time. Sensitivity of influenza virus Antigen by colloidal gold poor, mainly used in the screening test for influenza a virus. Influenza virus nucleic acid detection high sensitivity and specificity, is the gold standard for diagnosis of viral pneumonia. For example, information on 4 cases of swine flu screening test for virus Antigen test was negative, six cases of influenza a virus RNA positive. Therefore, high-risk patients with swine flu should be repeatedly reviewed influenza antigens or viral nucleic acid testing. The information on three cases of swine flu and the other three cases could not confirm whether H7N9 or H5N1. Main reasons and clinical viral nucleic acid testing projects, specimen submission channel flow and other factors. ${ }^{6}$ Past swine, H7N9, H5N1 influenza as a class b infectious disease, and take a class infectious diseases preventive and control measures, Guo Weiji control 28 disarm the disease group a regulations. Large doses of oseltamivir (150 mg/times, 2 times a day), on the basis of long-term treatment (at least 7-10days), ${ }^{7}$ influenza virus Detox time still extended, severe pneumonia, impaired immune function lead to effective virus removal, or cannot effectively absorb the antiviral drug-related. BALF nucleic acid positive influenza a virus specimens, undoubtedly increase the enthusiasm of staff fear and active care..$^{5,8}$ BALF samples after treatment against influenza virus nucleic acid positive reflect viral activity and pathogenicity, disputed. ${ }^{9,10}$ At this point, the isolation of influenza a virus and determine its activity. ${ }^{11}$ Home to carry out the technique, refer to the incubation period of influenza viruses reasonably isolated. The morbidity $>$ after 7 days in hospital, does not have a contagious influenza virus.

Take the standard precautions, medical staff in this ward were not infected with swine flu. GM has limited value in serum of patients with non-severe agranulocytosis is recommended based on Bronchoscopic diagnosis IPA. ${ }^{12}$ Developing severe influenza viral pneumonia in patients above 60 years old, or suffering from multiple diseases, such as COPD, diabetes, chronic kidney disease. ${ }^{1-3}$ Severe cases with invasive pulmonary aspergillosis (IPA), a high mortality rate, this case 3 , case 4,5 patients were dead. ${ }^{13,14}$ Large doses of corticosteroids are IPA not only risk factors also increase mortality in patients with severe influenza virus pneumonia. ${ }^{7,15}$

Hormone lack secondary to viral pneumonia improve the curative effect of pulmonary fibrosis and the adverse effects of increased pulmonary infection, do not recommend hormones for the treatment of patients with influenza virus pneumonia. ${ }^{16-18}$ This group of patients with paroxysmal cough violently, mechanical ventilation during the fight against severe, 2 cases of tension pneumothorax (50\%). Such patients of ventilator-induced lung injury (VILI), with the exception of influenza virus-induced severe challenges to protective strategy of mechanical ventilation in patients with ARDS,,$^{19,20}$ and cough after viral infection of high sensitivity syndrome (CHS) about. ${ }^{21,22}$

Therefore, diphenhydramine, and dextromethorphan, codeine and other drugs, not only to mitigate the adverse effects of intractable cough due to $\mathrm{CHS}^{23}$ and avoid relying too much on deep sedation to improve human-machine synchronization to harm. ${ }^{24}$ One-sided pursuit high oxygen and index led to evacuation breathing machine delay, especially concerns flu virus infection sex and take closed sucking phlegm, and fear pipeline accident off implementation deep calm and real rational constraints, measures, ${ }^{24,25}$ deterioration phlegm liquid drainage not Chang against, following sent to multiple resistance drug Bowman not moving Bacillus mainly of breathing machine correlation pneumonia, ${ }^{26}$ and blood flow infection, is patients mortality home high not drop of important factors one of.

Study on the shortcomings of the present study is limited to a single Ward and small number of cases.

\section{Local hospital fund projects}

Shandong Science Fund (ZR2013HM088), Temple Research Fund (UF201404), national key specialties construction of clinical projects (2011-873).

\section{Acknowledgements}

None.

\section{Conflicts of interest}

Author declares there are no conflicts of interest.

\section{Funding}

None.

\section{References}

1. Human Avian Influenza Treatment Program (Revised Edition 2005) Chinese Journal of Medicinal Guide. 2006;2:177-179.

2. Influenza A H1N1 Influenza treatment program. Chinese Journal of Critical Care Medicine (electronic version). 2009;1:19-24.

3. Human infection H7N9 avian influenza diagnosis and treatment program. Infectious Diseases Information. 2014;1:1-4.

4. Guidelines for the Diagnosis and Treatment of Influenza. Journal of Community Medicine. 2011;5:66-74.

5. Pan $\mathrm{H}$, Zhang $\mathrm{X}, \mathrm{Hu}$ J, et al. A case report of avian influenza $\mathrm{H} 7 \mathrm{~N} 9$ killed a young doctor in Shanghai, China. BMC Infect Dis. 2015;15:237.

6. Unexplained pneumonia case monitoring, troubleshooting and management guidelines. 2013.

7. Abdel-Ghafar AN, Chotpitayasunondh T, Gao Z, et al. Writing Committee of the Second World Health Organization Consultation on Clinical Aspects of Human Infection with Avian Influenza, Update on avian influenza A (H5N1) virus infection in humans. $N$ Engl J Med. 2008;358(3):261-273.

8. Longxing Ying, Zeng Weizhong, Li Shunwu. Clinical Nursing of 34 Cases of Severe Influenza A H1N1. Journal of Nursing. 2010;16(28):60-62.

9. Fielding J E, Kelly HA, Mercer GN, et al. Systematic review of influenza A (H1N1) pdm09 virus shedding: duration is affected by severity, but not age. Influenza Other Respir Viruses. 2014;8(2):142-150.

10. Kwong J C. Editorial Commentary: Symptoms and Viral Shedding in Naturally Acquired Influenza Infections. Clin Infect Dis. 2016;62(4):438-439.

11. Rodriguez A, Alvarez-Rocha L, Sirvent JM, et al. Recommendations of the Infectious Diseases Work Group (GTEI) of the Spanish Society of Intensive and Critical Care Medicine and Coronary Units (SEMICYUC) and the Infections in Critically Ill Patients Study Group (GEIPC) of the Spanish Society of Infectious Diseases and Clinical Microbiology (SEIMC) for the diagnosis and treatment of influenza $\mathrm{A} / \mathrm{H} 1 \mathrm{~N} 1$ in seriously ill adults admitted to the Intensive Care Unit. Med Intensiva. 2012;36(2):103-137.

12. Patterson TF, Thompson GR, Denning DW, et al. Practice Guidelines for the Diagnosis and Management of Aspergillosis: 2016 Update by the Infectious Diseases Society of America. Clin Infect Dis. 2016; 63(4):e1e60 
13. Analysis of risk factors of prognosis in patients with acute respiratory distress syndrome. Journal of Shandong University (Health Sciences). 2012;3:93-95.

14. Liu Han, Zhang Jianning, Du Binfeng. Invasive pulmonary fungosis in 4 cases. Chinese Journal of Infection and Chemotherapy. 2010;10(1):57-58.

15. Kim S H, Hong SB, Yun SC, et al. Corticosteroid treatment in critically ill patients with pandemic influenza A/H1N1 2009 infection: analytic strategy using propensity scores. Am J Respir Crit Care Med. 2011;183(9):1207-1214.

16. QIN Tie-he, LI Yi-min, WANG Zong-hong. Study on some problems in the diagnosis and treatment of human infection with H7N9 avian influenza. Guangdong Medicine. 2014;3:333-335.

17. Influenza influenza antiviral treatment and prevention of Chinese experts consensus. General practice and education. 2016;2:124-130.

18. Lamontagne F, Quiroz Martinez H, Adhikari NK, et al. Corticosteroid use in the intensive care unit: a survey of intensivists. Can J Anaesth. 2013;60(7):652-629.

19. Evaluation of mechanical ventilation in patients with ARDS from autopsy of lung tissue. Journal of Shandong University (Health Sciences) $.2010 ; 2: 161-163$.
20. Yang Yi, Qiu Haibo. Treatment of acute respiratory distress syndrome: the need to follow the ten principles. Chinese Journal of Critical Care Medicine. 2015;1:33-38.

21. Dicpinigaitis PV. Effect of viral upper respiratory tract infection on cough reflex sensitivity. J Thorac Dis. 2014;6(Suppl 7):S708-711.

22. Dicpinigaitis PV, Dhar S, Johnson A, et al. Inhibition of cough reflex sensitivity by diphenhydramine during acute viral respiratory tract infection. Int J Clin Pharm. 2015;37(3):471-474.

23. Song WJ, Chang YS, Morice AH. Changing the paradigm for cough: does 'cough hypersensitivity' aid our understanding? Asia Pac Allergy. 2014;4(1):3-13.

24. Shehabi Y, Bellomo R, Reade MC, et al. Early intensive care sedation predicts long-term mortality in ventilated critically ill patients. $\mathrm{Am} \mathrm{J}$ Respir Crit Care Med. 2012;186(8):724-731.

25. Kamal Aktar, Han Hui, Ding Shifang. Clinical analysis of 17 patients with severe myasthenia gravis. Chinese Journal of Critical Care Medicine. 2015;4:306-309.

26. Kalil A C, Metersky ML, Klompas M, et al. Management of Adults With Hospital-acquired and Ventilator-associated Pneumonia: 2016 Clinical Practice Guidelines by the Infectious Diseases Society of America and the American Thoracic Society. Clin Infect Dis. 2016;63(5):e61-e111. 